\title{
Exploratory Analysis of Korean Elementary Preservice Teachers' \\ Mathematics Teaching Efficacy Beliefs
}

\section{Dohyoung Ryang}

The University of North Carolina at Greensboro

\begin{abstract}
This study compared mathematics teaching efficacy beliefs of elementary preservice teachers in South Korea. Data was collected by administering a Korean-translated Mathematics Teaching Efficacy Beliefs Instrument to 106 elementary preservice teachers in a national university of education in South Korea. Analysis of data revealed that preservice teachers at the end point (seniors) of the program had significantly lower personal efficacy and outcome expectancy in mathematics teaching than those of preservice teachers at the beginning (sophomores) of the program. Heavy content coursework and cultural influence are discussed as potential factors to this result.
\end{abstract}

Keywords: culture, outcome expectancy, personal efficacy, preservice teachers, mathematics

Efficacy belief is an idea with significant implications in education. Teacher efficacy is an important construct to predict their actual efficacious teaching. An individual's sense of efficacy is a judgment of his or her capabilities to accomplish certain levels of performance. A teacher's sense of efficacy is a judgment of his or her capabilities to bring desired outcomes of student engagement and learning, even among those students who may be difficult or unmotivated (Tschannen-Moran \& Hoy, 2001). Efficacy beliefs are somewhat resistant to change, once they are established (Tschannen-Moran, Woolfolk Hoy, \& Hoy, 1998). However, they are more open to change in preservice teachers (Hoy \& Spero, 2005). Recently, preservice teachers' efficacy beliefs are more interested than those of inservice teachers.

Since teacher efficacy is context specific (Bandura, 1986), academic domain specific (Bandura, 1997), and subject-matter specific (Tschannen-Moran et al., 1998), efficacy in a specific subject, for example mathematics, is assumed to be a powerful method of predicting preservice teachers' future ability to teach mathematics. Absolutely, an instrument is needed for measuring efficacy beliefs in mathematics teaching. Enochs, Smith, and Huinker (2000) established validity of the Mathematics Teaching Efficacy Beliefs Instrument (MTEBI) for U. S. elementary preservice teachers. The MTEBI has been widely used in studies that verified the importance of mathematics teaching efficacy as a construct.

Since efficacy beliefs may vary culture to culture (Lin, Gorrell, \& Taylor, 2002), despite the MTEBI's contribution to the studies on mathematics teaching efficacy in Western cultures, the instrument itself has limitation to be used in non-Western cultures. Information to mathematics teaching efficacy of non-Western cultures are little known so far. The current study explores mathematics teaching efficacy beliefs in South Korea. Because of linguistic and cultural differences between countries, an instrument developed in a source culture should be tested in a target culture. The purpose of this study is first to explore the MTEBI for South Korea and then to investigate mathematics teaching efficacy beliefs of Korean 
elementary preservice teachers at the beginning (sophomore) and end (senior) of their teacher education program. The research questions guiding this study are:

(1) Is the MTEBI an appropriate instrument for the use in studying Korean preservice teachers' mathematics efficacy?

(2) How does mathematics teaching efficacy beliefs of Korean elementary preservice teachers differ between the entry and the end group of the program?

\section{Related Research}

Based on Bandura's (1977) self-efficacy conceptualization, Gibson and Dembo (1984) developed the Teacher Efficacy Scale which measures teachers' general sense - not in a specific subject matter - of efficacy with the two subscales: (Personal) Teaching Efficacy (TE or PTE) and General Teaching Efficacy (GTE). This Gibson and Dembo's scale has been widely used in studies that verified the importance of teacher efficacy as a construct (Tschannen-Moran et al., 1998). For example, highly efficacious teachers use a greater variety of instructional strategies and are more likely to use inquiry and student-centred teaching strategies (Riggs \& Enochs, 1990; Wenta, 2000), while teachers of low level efficacy are more likely to use teacher-directed strategies such as lectures and textbook reading (Czerniak, 1990). In addition, teacher efficacy has positive effects on a teacher's effort and persistence in the face of difficulties (Soodak \& Podell, 1993), personal commitment to teaching and students (Coladarci, 1992), and openness to new methods of teaching and positive behaviours (Ghaith \& Yaghi, 1997). In addition, a teacher's higher level of efficacy lead to better student outcomes such as academic achievement (Moore \& Esselman, 1992) and motivation (Midgley, Feldlaufer, \& Eccles, 1989).

Using the Enoch, Smith, and Huinker's MTEBI, research verified that mathematics teaching efficacy is an influential factor in a preservice teacher's efficacy beliefs in mathematics teaching. For example, preservice teachers' mathematics methods courses and field experiences are factors in mathematics teaching efficacy (Utley, Bryant, and Moseley, 2005; Wenner, 2001), completion of mathematics methods courses that focus on reformoriented teaching leads to stronger commitments by preservice teachers to reform-oriented mathematics (Cakiroglu, 2000), and mathematics instructional strategies are associated with mathematics teaching efficacy (Swars, 2005). Research also revealed that mathematics teaching efficacy beliefs are negatively related to mathematics anxiety (Gresham, 2008; Swars, Danne, \& Giesen, 2006; Swars, Smith, Smith, \& Hart, 2009).

In the past two decades, Gorrell and his colleagues (Gorrell, Ares, \& Boakari, 1998; Gorrell, Hazareesigh, Carlson, \& Sjoblom, 1993; Gorrell \& Hwang, 1995; Gorrell \& Dharmadasa, 1996; Lin \& Gorrell, 2001; Lin, Gorrell, \& Taylor, 2002) investigated teacher efficacy in diverse cultures including the U. S., Sweden, Sri Lanka, South Korea, and Taiwan. The result of these studies indicates that a teacher education program may lead to greater personal efficacy due to an increase in teaching skills but less general efficacy beliefs due to increased awareness of the general difficulties of teaching as a profession. However, teacher efficacy was very much subject to cultural influences and thus (preservice) teachers in different countries may have conceptually different expectations of teaching. (cf. Lin \& Gorrell, 2001; Lin, Gorrell, \& Taylor, 2002). 
In comparison of Western and Eastern cultures, Gorrell et al. (1993) found that U. S. preservice teachers had more positive general teaching efficacy compared with Sri Lankan and Swedish teachers while Sri Lankan teachers' personal teaching efficacy is relatively higher than that of U. S. preservice teachers. Similarly, Gorrell and Dharmadasa (1994) found that Sri Lankan preservice teachers' personal efficacy is higher than that of inservice teachers while there is no differences in general efficacy between the two groups. In another study, Campbell (1996) compared teacher efficacy of preservice and inservice teachers in Scotland and America, concluding that the two countries are comparable in fostering teacher efficacy in their preservice and inservice teacher education programs.

Culturally divergent perspectives can lead to responses differently to the efficacy measurement. The standard teacher efficacy measure, Gibson and Dembo's (1984) Teacher Efficacy Scale has the two factorial variables. However, other studies indicate that the factorial structure of the Gibson and Dembo's scale varies with the cultures in which the instrument was administered. For example, Lin and Gorrell (2001) suggested a four-factor structure for Taiwanese teachers. Similarly, Ho and Hau (2004) suggested using a four-factor model for Chinese teachers and a three-factor model for Australian teachers. Brouwers and Tomic (2003) tested the two, three, and four-factor models using confirmatory factor analysis on 540 Dutch teachers. They found that the four-factor model fitted the data better than the other models but fit indices did not reach the recommended level of an adequate model. These results indicate that the TES may not suitable for obtaining precise and valid information about teacher efficacy beliefs in some cultures.

Despite the research effort on teacher efficacy during the past decades, there are a limited number of studies related to mathematics teaching efficacy especially conducted in nonWestern cultures. For example, Cakiroglu (2008) reported that preservice Turkish teachers tend to have a stronger belief that teaching can influence student learning when compared with preservice teachers in the U.S. In addition, there are few studies validating the MTEBI in non-Western cultures. Alkhateeb (2004) translated the MTEBI into Arabic to verify its accuracy in Jordan, a Middle-East Asian country. The study reported Cronbach's alpha 84 for the PMTE and .75 for the MTOE. Another study was conducted by Ryang (2007) who translated and tested the MTEBI for Korean preservice teachers. He reported that the MTEBI's does not have two-factor structure as supposed within Korean preservice teachers. However, this result is perhaps due to the mixed data from both elementary and secondary preservice teachers. He finally recommended conducting research separately for elementary and secondary preservice teachers.

\section{Theoretical Framework}

A theoretical base of self-efficacy is Bandura's Social Learning Theory (1977), later called the Social Cognitive Theory (1986), and revised to the Situated Cognitive Learning Theory (1997). Self-efficacy is the individual's organizing the necessary actions in order to manage probable situations and his beliefs about the skill of realizing these actions (Bandura, 1997). Self-efficacy is conceptualized by two dimensions of Self Efficacy (Researchers later prefer to call it Personal Efficacy or shortly PE) and Outcome Expectancy (OE). The PE is an individual's beliefs that influence his or her capability to cope with change in situated 
experiences. The $\mathrm{OE}$ is a generalized expectation that influences an individual's actionoutcome contingencies based on perceived life experiences. He asserted that an individual's behaviour is influenced by both personal efficacy and outcome expectancy and an individual's behaviour can better predict levels of success through one's efficacy beliefs than through actual accomplishments. Both $\mathrm{PE}$ and $\mathrm{OE}$ differentiate the situation and the context of that situation (Bandura, 1986). Therefore, human behaviour is a product of one's perceived expectancy that a specific behaviour will result in a desirable outcome in conjunction with one's belief in one's capability to perform that behaviour.

Gibson and Dembo (1984) applied Bandura's efficacy theory to the area of teacher education. They stated that "...teachers who believe student learning can be influenced by effective teaching (outcome expectancy) and who also have confidence in their own teaching abilities (self-efficacy) should persist longer, provide a greater academic focus in the classroom, and exhibit different types of feedback concerning their ability to influence student learning" (p. 570). Based on this theoretical strand, Gibson and Dembo (1984) actually developed the Teacher Efficacy Scale (TES) which has the Personal Teaching Efficacy (TE or PTE) subscale and the General Teaching Efficacy (GTE) subscale. The PTE corresponds to Bandura's SE, and the GTE corresponds to Bandura's OE.

This study uses the MTEBI which has the two subscales of the Personal Mathematics Teaching Efficacy (PMTE) and the Mathematics Teaching Outcome Expectancy (MTOE). The PMTE, which corresponds to Bandura's SE and Gibson and Dembo's TE, identifies a teacher's beliefs about his or her capability to teach mathematics effectively. The MTOE, which corresponds to Bandura's OE and Gibson and Dembo's GTE, identifies a teacher's beliefs that effective teaching will have a positive influence on students' mathematics achievement.

\section{Overview of Elementary Teacher Education in South Korea}

Elementary teacher education program is a 4-year program in Korea. Elementary teachers are nurtured in 13 different sites. Among them, 12 programs are housed in National (public) Universities of Education (NUE) and one program in a private university. The NUEs usually run exclusively elementary teacher education programs; however, Korea National University of Education (KNUE) is a comprehensive university of education which houses both elementary and secondary teacher education program. Also, an NUE was most recently merged into a national university nearly located.

An NUE houses many departments relating to the different subjects taught in elementary schools. A department, for example, Department of Mathematics Education manages a further study track which offers more specific courses for preservice teachers to prepare knowledge in the subject of mathematics. The first year of the elementary teacher education program covers general education and prepares them for further study in a specific subject area from the second year. Elementary teachers in Korea teach all subjects in a school; taking a further study track is not a requirement but an option. However, they usually enroll in a further study track from the sophomore year to focus on one subject more than the others.

The composition and coursework of the programs in different sites are not very different. The KNUE graduation requirement is briefly described here. To complete the program, 
elementary preservice teachers need to earn 140 credit hours for graduation. At least 120 credit hours must come from liberal arts, pedagogy, contents, methods, electives, and field experience. They take content and method courses in various subjects. Preservice teachers in the mathematics further study track takes an additional 15 credit hours of courses in mathematics such as Calculus, Set theory, Modern Algebra, Analysis, Geometry, Topology, Statistics. These advanced mathematics courses are set with introductory level of two semester credit hours. Preservice teachers also take six credit hours of methods courses such as the History of Mathematics/Education, Mathematics Teaching Materials, or the Psychology of Mathematics Learning. In addition to coursework, an elementary preservice teacher has clinical experiences at various points in the program. A typical format consists of a full-time 2-week observation (1 credit hour) in the sophomore year, a full-time 2-week participation ( 1 credit hour) in the junior year, and a full-time 4 week professional practice (2 credit hours) in the first semester of the senior year. Often, observational practice and participating practice occur together, where preservice teachers learn by observation of mentor teachers' teaching and classroom management, and by teaching demonstration.

\section{Methods}

\section{Participants}

Participants are of 106 Korean elementary preservice teachers in the mathematics further study track of an elementary teacher education program. Freshmen are assumed to be conceptually different from the sophomores, juniors and seniors, because they have not yet chosen a subject area track and have not had any teaching practice. Therefore, data were not collected from the freshmen. The sophomores are considered entry-level participants and the seniors are considered at the end of the mathematics teacher preparation. The sample for this research was composed of 35 sophomores, 30 juniors, and 41 seniors. The average age of participants was of 23.12 years $(\mathrm{SD}=3.41)$. One third $(33 \%)$ of participants were male; others $(67 \%)$ were females. All participants were voluntary, and were given the informed consent form before the study.

\section{Instrumentation}

Korean version of the Mathematics Teacher Efficacy Beliefs Instrument (MTEBI) was used for this study. The MTEBI consists of 21 items within the two scales (13 items in the PMTE and 8 items in the MTOE) for a total of 21 items. Each item has five choices: Strongly Disagree (SD), Disagree (D), Uncertain (UN), Agree (A), and Strongly Agree (SA). Responses were scored by means of a five-point Likert scale from 1 for SD though 5 for SA. The MTEBI was translated into Korean by the author and two qualified bilingual graduate students. Some items were modified in order to fit the Korean language and culture. Each item was coded by the item number with $\mathrm{P}$ (indicating personal efficacy) or $\mathrm{O}$ (indicating outcome expectancy). For example, P2 indicates that Item 2 belongs to the PMTE scale; O1 indicates that Item 1 is of MTOE. Principal component analysis suggested removing two items, one item from each PMTE and MTOE scale (see discussion on factor analysis below). 
Possible scores, thus, range from 12 to 60 on the PMTE scale, and 7 to 35 on the MTOE scale. The alpha reliabilities of the subscales were .86 for the PMTE and .66 for MTOE.

\section{Data Analysis}

After exploring the factor structure using principal component analysis, one-way analysis of variance (ANOVA) model was used to analyse the data. With related to the normality assumption for the use of ANOVA model, although there is no unified agreement on the minimal size of a group in the model, 25 individuals per group is acceptable (Lomax, 2001). The Kruskal-Wallis test, nonparametric one-factor ANOVA model, might be considered as an alternative analysis method. However, when the normality assumption is met, or even slightly violated, the parametric ANOVA is more powerful than Kruskal-Wallis test (Lomax, 2001). In this study, each group (sophomore, junior, and senior) has 35, 30, and 41 subjects, respectively. Further, the P-P plots of all items and the MTOE and PMTE scales suggested the normal distribution of the data (see Figures 1 and 2).

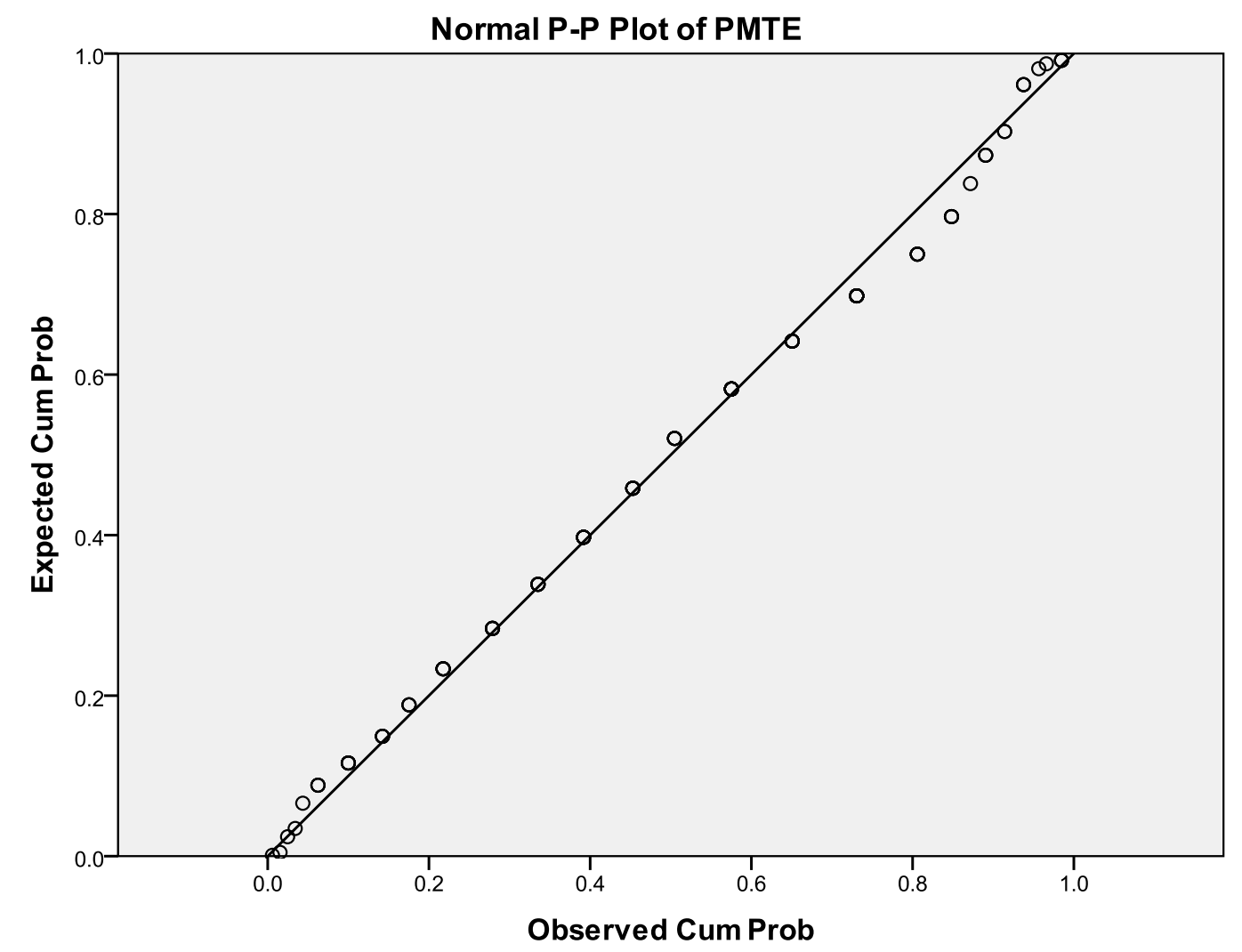

Figure 1. Normal P-P plot of the PMTE scale*.

*Note: The observed cumulative probability of the PMTE scale is approximately onto the theoretically assumed probability line. 


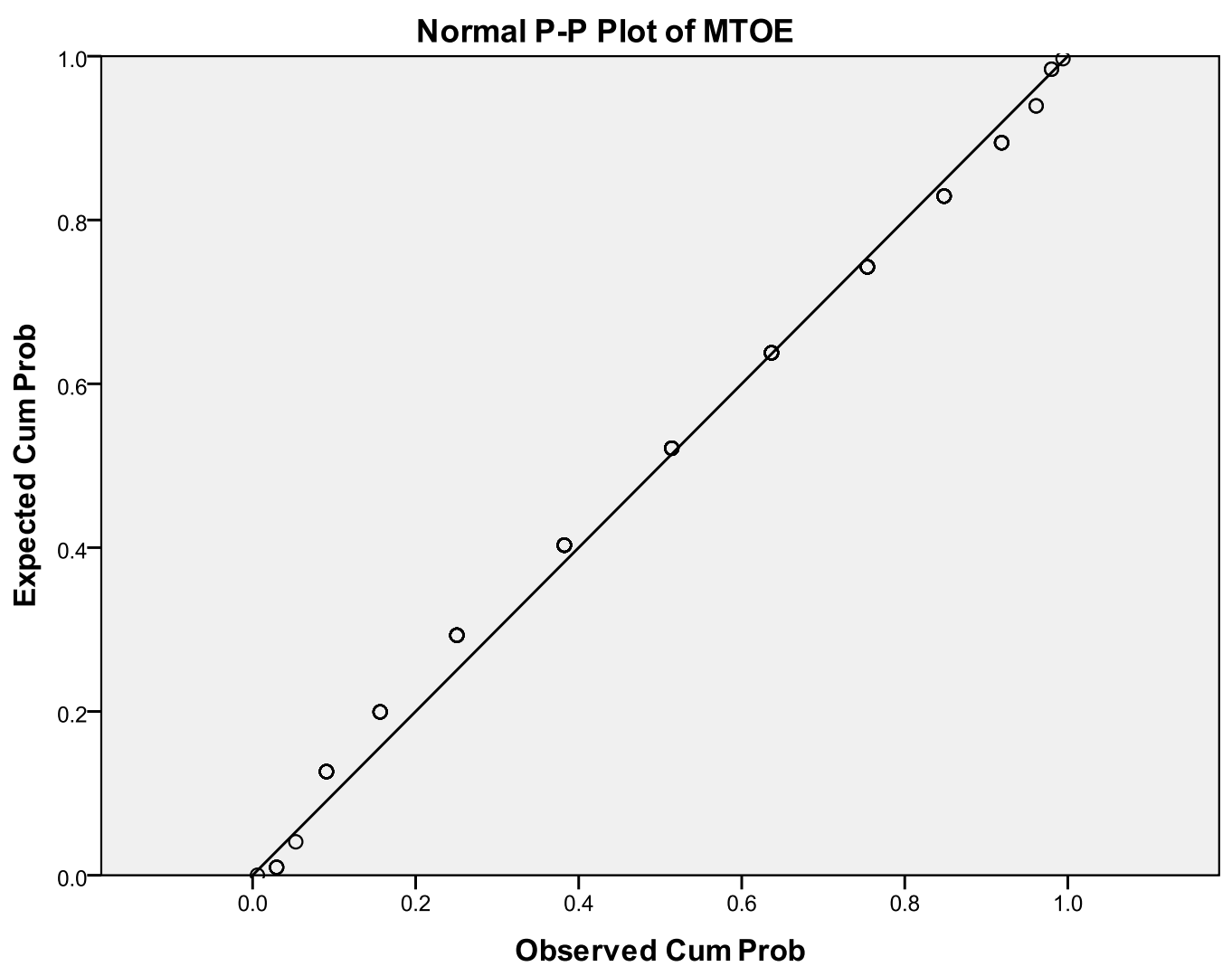

Figure 2. Normal P-P plot of the MTOE scale.

*Note: The observed cumulative probability of the MTOE scale is approximately onto the theoretically assumed probability line.

\section{Results}

\section{Factor Analysis}

Principal component analysis (PCA) was used to explore the factor structure on the data. The one-factor model of each PMTE and MTOE scale was tested first, and then, the twofactor model on the whole items was tested. For use of factor analysis, the two assumptions of sampling adequacy and sphericity of the data should be met. The Kaiser-Meyer-Olkin (KMO) sampling adequacy measures were .85 for the PMTE and .76 for the MTOE. Bartlett's test of sphericity was also significant for the PMTE $\left(\chi^{2}=492.48, d f=78, p<\right.$ $0.001)$ and the MTOE $\left(\chi^{2}=137.73, d f=28, p<0.001\right)$.

A scree plot is usually used to determine the number of factors. A scree plot is a line graph of eigenvalues of potential components in descending order (Hill \& Lewicki, 2007). It is recommended in a scree plot finding where the smooth decrease of eigenvalues appears to level off to the right. The data is usually rotated in order to increase simplicity and clarity of the factor structure. In this study, the two factors of PMTE and MTOE are theoretically designed from Bandura's personal efficacy and outcome expectancy which are intertwined with together (Bandura, 1986). That is, the PMTE and the MTOE are not independent but correlated to each other. Thus, suggested by Osborne and Costello (2005), promax rotation was used when the factors were extracted. PCA with promax rotation on the 13 PMTE items 
extracted components with eigenvalues 5.24, 1.15, 1.10, 1.02, and so on. Also, PCA with promax rotation on the $8 \mathrm{MTOE}$ items extracted components with eigenvalues $2.70,1.22$, 1.00 , and so on. On both extractions, the first eigenvalue was distinctively higher than others which smoothly decrease appearing to level off. The result indicated that the PMTE and MTOE scale has a one-factor structure.

Next, the two-factor model was tested on the whole 21 items. The KMO index was .84 , and Bartlett's sphericity test significant $\left(\chi^{2}=819.78, d f=210, p<0.001\right)$. PCA with promax rotation extracted six components with eigenvalues $6.61,2.11,1.44,1.21,1.13,1.03$, and so on. The first two eigenvalues were distinctively higher than the others which gradually decrease. The instrument thus has a two-factor structure. For seeing the pattern of the factor structure, PMTE items were coded by the initial P and the item number, and similarly for the MTOE items. Item 2 and Item 14 were, for example, coded by P2 and O14. The result of PCA showed that P2 and $\mathrm{O} 14$ were loaded to an inappropriate factor, that is, only $\mathrm{P} 2$ had loading to the component 2 and other P-initial items had loading to the component 1; O14 is similarly behaved. These two items were suggested to be removed.

After deleting P2 and O14, PCA with promax rotation was performed again for the 19 items. The component matrix was shown in Table 1. All P-initial items had loadings to the Component 1 and all O-initial items had loadings to the Component 2. Note that there are two items of potential weakness. Item P11 had loadings .347 to the Component 2, which is higher than the lowest factor loading .330. Also, the factor loading .330 of Item $\mathrm{O} 1$ is very isolated from other O-initial items' factor loadings. The Component 1 has the extraction sum 6.08 and explains $32 \%$ of variance; the Component 2 has the extraction sum 2.00 and explains $10.51 \%$ of variance. Thus, the Component 1 turned to be the PMTE and the Component 2 to be the MTOE.

Table 1

Principal component matrix

\begin{tabular}{lcc}
\hline & \multicolumn{2}{c}{ Component } \\
\cline { 2 - 3 } Item & 1 & 2 \\
\hline P15 & .748 & \\
P8 & .741 & \\
P19 & .729 & \\
P3 & .722 & \\
P21 & .646 & \\
P16 & .606 & \\
P18 & .591 & \\
P5 & .565 & \\
P6 & .524 & \\
P17 & .492 & $.347)$ \\
P11 & .480 & .745 \\
P20 & .470 & .661 \\
O9 & & .625 \\
O10 & & .616 \\
O13 & & .599 \\
O12 & & .580 \\
O7 & & .330 \\
O4 & & \\
O1 & & \\
\hline
\end{tabular}




\section{General Linear Model}

The PMTE mean scores of the sophomores, juniors, and seniors were looked gradually decease along the level in the program. In fact, the PMTE mean scores of sophomores, juniors, and seniors were 45.71, 42.90, and 42.34. Similarly, the MTOE mean scores were also gradually decreased from 26.17 via 25.47 to 25.21 . The significance of these differences was tested with a general linear model.

One-way ANOVA model was used to compare the mean scores of sophomores, juniors, and seniors on each scale, where the factor was Level (SO, JR, SR) and the dependent variables was PMTE or MTOE. Levene's test of equality of error variance first performed to test the null hypothesis that the error variance of the dependent variable is equal across the Level. The result of Levene's test on PMTE and MTOE were respectively $F(2,103)=0.54, p$ $=.58$ and $F(2,103)=0.12, p=.88$, indicating that PMTE and MTOE score distributions are not different across the level. The ANOVA results (see Table 2) indicated that the Level has a significant effect $(p=0.036)$ on PMTE, small effect size $\left(\eta^{2}=.062\right)$, and moderate power $(1-$ $\beta=.632)$. The Bonferroni post hoc test revealed that there is a significant difference between SO and SR $(p=.042)$ on the PMTE scores. The results also indicated that Level has a significant effect $(p=0.018)$ on MTOE, small effect size $\left(\eta^{2}=.075\right)$, and moderate power $(1-$ $\beta=.726)$. The Bonferroni post hoc test revealed that there is a significant difference between SO and SR $(p=.016)$ on the MTOE scores.

Table 2

Analysis of variance for the PMTE and MTOE

\begin{tabular}{rrrrrrrr}
\hline Source & \multicolumn{1}{c}{$S S$} & $d f$ & $M S$ & $F$ & $p$ & $\eta^{2}$ & $1-\beta$ \\
\hline PMTE & & & & & & & \\
Level & 236.08 & 2 & 118.04 & 3.43 & .036 & .062 & .632 \\
Error & 3547.06 & 103 & 34.44 & & & & \\
Total & 407.00 & 106 & & & & & .726 \\
MTOE & & & & & & \\
Level & 76.56 & 2 & 38.28 & 4.20 & .018 & .075 & \\
Error & 938.88 & 103 & 9.12 & & & & \\
Total & 68370.00 & 106 & & & & &
\end{tabular}

Note: $S S=$ Sum of square, $d f=$ degree of freedom, $M S=$ Mean square, $\beta=$ Type II error

Responses of preservice teachers were also looked for item-wise investigation. The mean scores of each group in each item were calculated (see Table 3). In all PMTE and MTOE items, the senior mean scores were smaller than those of the sophomores. Then, multivariate analysis of variance (MANOVA) was conducted in each scale. The MANOVA results indicated that the Level had no significant effect in the PMTE items (Wilks $\lambda=.70, F=1.50$, $p>.07, \eta^{2}=.16,1-\beta=.95$ ), and in the MTOE (Wilks $\lambda=.84, F=1.27, p>.22, \eta^{2}=.08,1-$ $\beta=.75$ ). However, follow-up univariate ANOVA revealed that Items 1,4 , and 11 were statistically significant. 
Table 3

Mean for Each Item by Level

\begin{tabular}{llccc}
\hline \multirow{2}{*}{ Item } & Brief Description & \multicolumn{3}{c}{ Level } \\
\cline { 4 - 5 } & PMTE & SO & JR & SR \\
3 & Teach mathematics as well as most subjects & 3.97 & 3.60 & 3.71 \\
5 & Teach mathematics concepts effectively & 3.34 & 3.10 & 3.10 \\
6 & Monitoring mathematics activities & 3.74 & 3.40 & 3.41 \\
8 & Teach mathematics ineffectively & 3.97 & 3.60 & 3.78 \\
11 & Understand mathematics concepts well & $3.69^{*}$ & $3.83^{*}$ & $3.34^{*}$ \\
15 & Use manipulatives to explain mathematics & 3.86 & 3.77 & 3.59 \\
16 & Answer students' questions & 3.94 & 3.90 & 3.71 \\
17 & Skills to teach mathematics & 4.06 & 4.03 & 3.78 \\
18 & The principal to evaluate mathematics teaching & 3.20 & 2.70 & 3.15 \\
19 & Help the student understand mathematics better & 3.97 & 3.63 & 3.51 \\
20 & Welcome student questions & 4.23 & 3.93 & 3.88 \\
21 & Turn students on to mathematics & 3.74 & 3.40 & 3.39 \\
MTOE & & & & \\
1 & Teacher's extra effort & $3.63^{*}$ & $3.30^{*}$ & $2.95^{*}$ \\
4 & More effective teaching approach & $4.17^{*}$ & $4.07^{*}$ & $3.83^{*}$ \\
7 & Ineffective mathematics teaching & 3.03 & 3.10 & 2.95 \\
9 & Student's mathematics background & 4.00 & 3.90 & 3.80 \\
10 & Teacher's extra attention & 3.60 & 3.67 & 3.44 \\
12 & Responsibility for students' achievement & 4.03 & 3.93 & 3.80 \\
13 & Teacher's mathematics teaching effectiveness & 3.71 & 3.50 & 3.41 \\
\hline & & & &
\end{tabular}

Note. $\mathrm{SO}=$ Sophomore, $\mathrm{JR}=$ Junior, $\mathrm{SR}=$ Senior, $\mathrm{M}=\mathrm{Man}, \mathrm{W}=$ Woman; $* p<.05$

\section{Discussion}

\section{Factor Structure of the Instrument Responses}

In this study, the result of exploratory factor analysis indicated that the two-factor structure based on Bandura's cognitive learning theory was not perfectly set but reasonably acceptable after deleting the two items which were cross-loaders. One of those two items was Item 2 (I will continually find better ways to teach mathematics), which was P-initial but loaded to the MTOE. The other was Item 14 (If parents comment that their child is showing more interest in mathematics at school, it is probably due to the performance of the child's teacher), which was O-initial but loaded to the PMTE.

This result implied that the participants' perspective to "finding better ways to teach mathematics" in Item 2 is something that a teacher should definitely do. In other words, this 
sense of efficacy is expanded to a general trait of a teacher in the Korean education community, rather than staying in the level of personal perception. However, in Item 14, the preservice teachers might regard a situation as a specific case rather a general trait. Perhaps they were not yet aware of parent involvement at school. Korean preservice teachers might have stronger beliefs that students' interest in mathematics at school can be detected more easily by a school teacher than by a student's parents. But, a qualitative research is necessary for verifying this conjecture.

Though Item 2 and Item 14 were deleted in this study, a future study can retake these items with more precise translation and rigor analysis. Since these two items were loaded to the other component, a suggested solution is to restate the items with the other forms. That is, Item 2 is possibly more appropriate with the MTOE form, for example: If a teacher continually finds better ways to teach mathematics, then students do better in mathematics. In addition, Item 14 can be restated with the PMTE form, for example: I will effectively perform mathematics teaching. These suggested revisions also need to be tested in a future study.

An issue in factor structure is the existence of cross-loading items, which is an item that loads at .32 or higher on two or more factors (Tabachnick \& Fidell, 2001). If there are several cross loaders, the items may be poorly written or the a priori factor structure could be flawed. A solid factor has five or more strong items of loading .5 or higher (Osborne \& Costello, 2005). In Table 1, all P-initial items loaded to the PMTE with loadings from .748 to .470; nine out of 12 items had loading higher than .5. Also, six of seven O-initial items had loadings to the MTOE from .745 to .580 . Thus, the instrument after deleting the two items appears to have a solid two-factor structure. However, a few items may still remain as potentially weak even after deleting the two items. The factor loading of Item 1 is .330, jumped down from the second last value .580 and close to the cut value .320 . Another potential weak item is Item 11, which had loadings .480 to PMTE and .347 to MTOE (see Table 1). Leaving this item in the instrument is a violation to Osborne and Costello's (2005) criterion and thus the validity is possibly slightly influenced. Nonetheless, the author decided to keep the item so that the reliability would not be decreased. However, a future study should retest Item 1 and Item 11 with rigor.

An instrument's validity and reliability is not completed within a single study but continually discussed along the time span as well as according to the cultural variance. Crosscultural research has investigated the appropriateness of transporting Western theories, constructs, and measuring instruments for use in non-Western cultures (Ho \& Hau, 2004). In this study, the factor structure of the Korean translated MTEBI was not confirmed but explored. A confirmatory study on the validity and reliability of the MTEBI is necessary in the next study so the MTEBI will be a more solid instrument.

\section{Mathematics Teaching Efficacy Beliefs of Korean Preservice Teachers}

This study compared Korean elementary preservice teachers' self-efficacy and outcome expectancy in mathematics teaching among three different groups of sophomores, juniors, and seniors. Overall, the sophomores had significantly lower mathematics teaching efficacy than the seniors. In particular, the responses of participants for individual items in the PMTE scale produced significance in Item 11 (I understand mathematics concepts well enough to be 
effective in teaching elementary mathematics). This item asks how confident preservice teachers are in their understanding of mathematics concepts. The seniors showed lower levels of confidence in understanding mathematics concepts than sophomores.

Similar to personal mathematics teaching efficacy, the seniors' mathematics teaching outcome expectancy was significantly lower than that of the sophomores. In particular, significant differences were produced from two items in the MTOE scale, Item 1 (When a student does better than usual in mathematics, it is often because the teacher exerted a little extra effort), and Item 4 (When the mathematics grades of students improve, it is often due to their teacher having found a more effective teaching approach). Sophomores had stronger perception than seniors that a teacher's additional works (extra effort and finding a new approach) will make a progress in students' outcome in mathematics learning.

This result does not directly indicate that preservice teachers' mathematics teaching selfefficacy and outcome expectancy change, but the result compares the differences between the groups. It might be possible that the seniors already had lower mathematics teaching efficacy when starting as sophomores compared to the sophomores in the study. Nonetheless, the study did not compare the two groups of entry and end point, but the three groups of sophomores, juniors, and seniors. In addition, the result is that the efficacy is lowest in the senior group and highest in the sophomore group. This result implies a high possibility that the efficacy beliefs of Korean elementary preservice teachers decreases as they proceed to the next year. A solid longitudinal study, however, is necessary to verify this conjecture in the future.

There is a pre-and-post study showing the change of mathematics teaching efficacy beliefs. For example, Cakiroglu (2000) found that U. S. preservice teachers' personal mathematics teaching efficacy increases during participation in coursework and teaching practice of a teacher education program. Also, Utley, Bryant, and Moseley (2005) found that U.S. elementary preservice teachers' personal mathematics teaching efficacy and mathematics teaching outcome expectancy increased significantly as mathematics teacher education in a methods course progressed. Both Cakiroglu (2000) and Utley et al.'s (2005) studies used the MTEBI, and showed that method courses and teaching practice are factors for increasing mathematics teaching self-efficacy and/or outcome expectancy. Research (cf. Gorrell \& her colleagues) has also reported on change of teachers' self-efficacy not in a specific subject matter but in general from the various cultures. Preservice teachers' selfefficacy tends to increase across a program because they better understand knowledge about the subjects and how to teach subjects. But, preservice teachers' outcome expectancy tends to decrease during the teacher education program because they have recognized the reality of teachers' profession as they experienced teaching practice in local schools and close to the end point of the program.

Based on the result of this study, Korean preservice teachers seem to have lost selfefficacy in mathematics teaching during their teacher preparation in the college. If then, the result of this study is inconsistent with the study of Cakiroglu, Utley et al. as well as the series of studies done by Gorrell and her colleagues. However, very recently, some U. S. researchers have discussed that preservice teachers' mathematics teaching efficacy beliefs may decrease during their teacher education program, especially during a content course. (Personal communication in the Annual Conference of the Research Council of Mathematics 
Learning, 2012). Thus, the effect of taking content courses to personal mathematics teaching efficacy beliefs remains as a future study. Similar to the case of personal mathematics teaching efficacy, mathematics teaching outcome expectancy of Korean preservice teachers also seems to decrease across a program. If then, the result of this study is inconsistent with the study of Cakiroglu, Utley et al. but consistent with the series of studies done by Gorrell and her colleagues.

\section{Contextual and Cultural Influences}

This study did not investigate change of, but difference in, mathematics teaching efficacy of Korean preservice teachers. However, it is highly probable that the differences would come from the change of math teaching efficacy. We here discuss an idea on the change of Korean preservice teachers' mathematics teaching efficacy beliefs. Efficacy beliefs may vary from the region of the world, and culture is the most influential factor to their own teacher efficacy (Lin, Gorrell, \& Taylor, 2002). The contextual and socio-cultural settings surrounding Korean elementary preservice teachers and the teacher education program can influence their personal efficacy and outcome expectancy in mathematics teaching.

In Korea, mathematics further study track in elementary teacher education program requires taking many content courses in all areas of mathematics including Set Theory, Calculus, Modern Algebra, Real Analysis, Probability and Statistics, Topology, and Geometry. Though these are set as 2-credit hour introductory level courses, understanding these various advanced mathematics is very demanding to the elementary preservice teachers. As the courses are progressed, incomprehensive understanding about mathematics has been accumulated. Although preservice teachers would have passed these courses by a narrow margin, they may not fully overcome the negative effects of this academic challenge. Thus, contextual settings of many advanced mathematics in Korean elementary teacher education program could link to lower personal mathematics teaching efficacy.

The quality of mathematics teaching depends on the knowledge, and therefore beliefs, of the teacher (Piel \& Green, 1993). Appropriate level of content knowledge should increase teachers' self-efficacy in mathematics teaching. Hill, Ball, and Schilling (2008) proposed a model of mathematical knowledge for teaching (MKT) consisting of six components among which specialized content knowledge (SCK) is mainly supported by taking advanced mathematics courses. SCK is the mathematical knowledge that allows teachers to engage in particular teaching tasks, including how to accurately represent mathematical ideas, provide mathematical explanations for common rules and procedures, and examine and understand unusual solution methods to problems (Ball, Hill, \& Bass, 2005). By this argument, mathematics content courses should not only discuss purely abstract mathematics but address also particular mathematics teaching tasks. Mathematics teacher educators should put efforts to develop specialized textbooks for the mathematics content courses listed above. Then, these adjusted content courses might be called Calculus for Teachers, Algebra for Teachers et cetera instead of just Calculus, Algebra, and so on.

Socio-cultural aspects of education can possibly influence teachers' outcome expectancy. Korean parents' educational support is a very important contributor to children's learning (Hwang, Lin, \& Gorrell, 1999). It is a reality that Korean parents spent a lot of money for 
their children's out-of-school private tutoring. Furthermore, the tutoring mainly goes to the subject of mathematics and English because these two subjects are a big portion of the college entrance exam. Therefore, Korean students already knew the mathematical concepts that they are expected to learn at a school. Also, Lew (2008) argued that Korean students were able to score well in an international mathematics competition whether due to a strong teacher variable or due to extensive out-of-school tutoring. Preservice teachers themselves had experienced such early prerequisite learning, and they would also be aware, with a teacher's perspective, soon that there is no new knowledge for their students and that increasing students' achievement would be very difficult because the achievement level has already been increased. This societal mood may lead to decrease preservice teachers' outcome expectancy in mathematics teaching. However, a qualitative study should verify this conjecture in the future.

Mathematics teaching efficacy is an important construct because such beliefs can predict preservice teachers' future behaviours in mathematics teaching. Teacher education programs should help preservice teachers develop a higher level of mathematics teaching efficacy. Therefore, understanding preservice teachers' efficacy beliefs is an important factor in knowing how or whether new teachers will succeed in their practice. The findings of the present study would give a hint to teacher educators in South Korea that they should look into and revise their teacher education programs.

\section{References}

Alkhateeb, H. M. (2004). Internal consistency reliability and validity of the Arabic translation of the Mathematics Teaching Efficacy Beliefs Instrument. Psychological Reports, 94. 833-838. doi: $10.2466 / \mathrm{pr} 0.94 .3 .833-838$

Ball, D. L., Hill, H. C., \& Bass, H. (2005, Fall). Knowing mathematics for teaching: Who knows mathematics well enough to teach third grade, and how can we decide? American Educator, 29, 14-22.

Bandura, A. (1977). Self-efficacy: Toward a unifying theory of behavioral change. Psychological Review, 84, 191-215. doi:10.1037//0033-295X.84.2.191

Bandura, A. (1986). Social foundations of thought and action: A social cognitive theory. Englewood Cliffs, NJ: Prentice Hall.

Bandura, A. (1997). Self-Efficacy: The exercise of control. New York: Freeman.

Brouwers, A., \& Tomic, W. (2003). A test of the factorial validity of the teacher efficacy scale. Research in Education, 69, 67-79.

Cakiroglu, E. (2000). Preservice elementary teachers' sense of efficacy in reform oriented mathematics. Unpublished doctoral dissertation, Indiana University.

Cakiroglu, E. (2008). The teaching efficacy beliefs of preservice teachers in the USA and Turkey. Journal of Education for Teaching, 34(1), 33-44. doi: $10.1080 / 02607470701773457$

Campbell, J. (1996). A comparison of teacher efficacy for pre and in-service teachers in 
Scotland and America. Education, 117(1), 2-11.

Coladarci, T. (1992). Teachers' sense of efficacy and commitment to teaching. Journal of Experimental Education, 60(4), 323-337. doi:10.1080/00220973.1992.9943869

Czerniak, C. M. (1990, April). A study of self-efficacy, anxiety, and science knowledge in preservice elementary teachers. Paper presented at the Annual Meeting of the National Association of Research in Science Teaching in Atlanta, GA, USA.

Enochs, L. G., Smith, P. L., \& Huinker, D. (2000). Establishing factorial validity of the mathematics teaching efficacy beliefs instrument. School Science and Mathematics, 100(4), 194-202. doi:10.1111/j.1949-8594.2000.tb17256.x

Ghaith, G., \& Yaghi, H. (1997). Relationship among experience, teacher efficacy, and attitudes toward the implementation of instructional innovation. Teaching and Teacher Education, 13, 451-458. doi:10.1016/S0742-051X(96)00045-5

Gibson, S., \& Dembo, M. H. (1984). Teacher efficacy: A construct validation. Journal of Educational Psychology, 76, 569-582. doi:10.1037//0022-0663.76.4.569

Gorrell, J., Ares, N. \& Boakari, F. (1998). Beliefs in school efficiency: An expansion of notions of teacher efficacy. Paper presented at the meeting of the American Psychological Society, Washington, DC.

Gorrell, J., Dharmadasa, K. H. (1994). Perceived self-efficacy of preservice and inservice Sri Lankan teachers. International Education, 24, 23-36.

Gorrell, J., Hazareesigh, N. A., Carlson, H. L., \& Sjoblom, L. S. (1993). A comparison of efficacy beliefs among preservice teachers in the United States, Sweden, and Sri Lanka. Paper presented at the Meeting of the American Psychological Association in Toronto, Canada.

Gorrell, J., \& Hwang, Y. (1995). A study of efficacy beliefs among preservice teachers in Korea. Journal of Research and Development in Education, 28(2), 101-105.

Gresham, G. (2008). Mathematics anxiety and mathematics teacher efficacy in elementary preservice teachers. Teaching Education, 19(3), 171-184. doi:10.1080/10476210802250133

Hill, H. C., Ball, D. L., \& Schilling, S. G. (2008). Unpacking pedagogical content knowledge: Conceptualizing and measuring teachers' topic-specific knowledge of students. Journal of Teacher Education, 59(5), 389-407.

Hill, T., \& Lewicki, P. (2007). Statistics methods and applications. Tulsa, OK: Statsoft.

Ho, I. T., \& Hau, K. T. (2004). Australian and Chinese teacher efficacy: Similarities and differences in personal instruction, discipline, guidance efficacy and beliefs in external determinants. Teaching and Teacher Education, 20(3), 313-323. doi:10.1016/j.tate.2003.09.009

Hoy, A. W., \& Spero, R. B. (2005). Changes in teacher efficacy during the early years of teaching: A comparison of four measures. Teaching and Teacher Education, 21(4), 343- 
356. doi:10.1016/j.tate.2005.01.007

Hwang, Y. S., Lin, H., \& Gorrell, J. (1999, November). Korean preservice teachers' efficacy. Paper presented at the meeting of the Mid-South Educational Research Association in Point Clear, AL.

Lew, H. C. (2008). Some characteristics of the Korean national curriculum and its revision process. In Z. Usiskin \& E. Willmore (Eds.), Mathematics Curriculum in Pacific Rim countries - China, Japan, Korea, and Singapore: Proceeding of a Conference (pp. 37-71). Charlotte, NC: Information Age Publishing.

Lin, H. L., \& Gorrell, J. (2001). Exploratory analysis of pre-service teacher efficacy in Taiwan. Teaching and Teacher Education, 17, 623-635. doi:10.1016/S0742$\underline{051 X(01) 00018-X}$

Lin, H, L., Gorrell, J., \& Taylor, J. (2002). Influence of culture and education on U.S. and Taiwan preservice teachers' efficacy beliefs. The Journal of Educational Research, 96, 37-46. doi:10.1080/00220670209598789

Lomax, R. G. (2001). An Introduction to statistical concepts for education and behavioral sciences. Hahwah, NJ: Lawrence Erlbaum Associates.

Midgley, C., Feldlaufer, H., \& Eccles, J. (1989). Change in teacher efficacy and student selfand task-related beliefs in mathematics during the transition to junior high school. Journal of Educational Psychology, 81, 247-258. doi:10.1037//0022-0663.81.2.247

Moore, W., \& Esselman, M. (1992). Teacher efficacy, power, school climate and achievement: A desegregating district's experience. Paper presented at the Annual Meeting of the American Educational Research Association, San Francisco, CA.

Osborne, J. W., \& Costello, A. B. (2005). Best practices in exploratory factor analysis: Four recommendations for getting the most from your analysis. Practical Assessment Research \& Evaluation, 10(7), 1-9.

Piel, J. A. \& Green, M. (1993). Attitudes toward five subjects areas: A comparison of elementary education and noneducation majors. North Carolina Journal of Teacher Education, 6, 28-37.

Riggs, I. M., \& Enochs, L. G. (1990). Toward the development of an elementary teacher's science teaching efficacy belief instrument. Science Education, 74, 625-637. doi:10.1002/sce.3730740605

Ryang, D. (2007). Soohak gyosoo hyonunngam dogoo MTEBI hangulpanui sinroidowa tadangdo. [Reliability and validity of the Korean-translated mathematics teaching efficacy beliefs instrument MTEBI]. Journal of the Korean Society of Mathematical Education Series A: The Mathematical Education, 46(3), 263-272.

Soodak, L. C., \& Podell, D. M. (1993). Teacher efficacy and student problem as factors in special education referral. Journal of Special Education, 27(1), 66-81. doi: $10.1177 / 002246699302700105$

Swars, S. L. (2005). Examining perceptions of mathematics teaching effectiveness among 
elementary preservice teachers with differing levels of mathematics teacher efficacy. Journal of Instructional Psychology, 32(2), 139-147.

Swars, S. L., Daane, C. J., \& Giesen, J. (2006). Mathematics anxiety and mathematics teacher efficacy: What is the relationship in elementary preservice teachers? School Science and Mathematics, 106(7), 306-315. doi:10.1111/j.1949-8594.2006.tb17921.x

Swars, S. L., Smith, S. Z., Smith, M. E., \& Hart, L. C. (2009). A longitudinal study of effects of a developmental teacher preparation program on elementary prospective teachers' mathematics beliefs. Journal of Mathematics Teacher Education, 12, 47-66. doi:10.1007/s10857-008-9092-X

Tabachnick, B. G., \& Fidell, L. S. (2001). Using multivariate statistics. Boston: Allyn and Bacon.

Tschannen-Moran, M., \& Hoy, A. W. (2001). Teacher efficacy: capturing an elusive construct. Teaching and Teacher Education, 17, 783-805. doi:10.1016/S0742$\underline{051 X(01) 00036-1}$

Tschannen-Moran, M., Woolfolk Hoy, A., \& Hoy, W. K. (1998). Teacher efficacy: Its meaning and measure. Review of Educational Research, 68, 202-248. doi: $10.2307 / 1170754$

Utley, J., Bryant, R., \& Moseley, C. (2005). Relationship between science and mathematics teaching efficacy of preservice elementary teachers. School Science and Mathematics, 105(2), 82-87. doi:10.1111/j.1949-8594.2005.tb18040.x

Wenner, G. (2001). Science and mathematics efficacy beliefs held by practicing and prospective teachers: A 5-year study. Journal of Science Education and Technology, 10(2), 181-187. doi:10.1023/A:1009425331964

Wenta, R. G. (2000). Efficacy of preservice elementary mathematics teachers. Unpublished doctoral dissertation, Indiana University.

\section{Authors}

Dohyoung Ryang, Assistant Professor, Department of Mathematics and Statistics, University of North Carolina at Greensboro, PO Box 26170, Greensboro, NC 27402; email: d_ryang@uncg.edu 